\title{
The Core Temperature Calculation of Emergency Load Change Cable Power Lines
}

\author{
Huang Xiaoyu \\ Economic and Technological Research Institute of State Grid Fujian Electric Power Co., Ltd., Fuzhou, \\ Fujian 350012 China
}

Keywords: Core temperature of power lines; emergency load; model

\begin{abstract}
In actual operation, when emergency power supply needs to emergency load for cables, cables may need full load or even overload operation. Such a running mode proposes a challenge for the power system safety. The transmission core temperature, as a decisive factor for insulating materials, shows the important significance on safeguarding safe operation of the power system. As a result, the core temperature calculation model of power lines is established to provide a reference for meeting the actual engineering demands and safe operation of the power system.
\end{abstract}

\section{Introduction}

For power lines in actual operation, core temperature of power lines is a decisive factor for insulating materials' lifetime and also one of important influencing factors to safeguard safe operation of the power system ${ }^{[1]}$. The findings show that core temperature of cable power lines is commonly affected by cable operation load and external environmental factors. When the cable load current is changed, the core temperature response of cables under the different laying environments still has an obvious difference ${ }^{[2]}$. Due to limitations of IEC 60287 standard and numerous algorithms, it has been hard to accurately master the actual core temperature of cable operation up to now.

With the high-speed development of national economy, all walks of life have more demands for power. Hence, in actual operation, when emergency power supply needs emergency load for cables, cables may need full load or even overload operation. However, in order to ensure cables won't break down because insulating materials are damaged, it is impossible for cables to operate for a long time under the full load or overload [3]. As a result, studying the lines' core temperature response characteristics in a short time when cable load takes place emergency changes shows the great actual value to solve emergency power supply problems.

In view of the above-mentioned analysis, the author proposes to introduce the equivalent Laplace hot-line model to the environmental parameter cable, subdivides the actually continuous change operation current as the equivalent step change current, and calculates the step change current heat at different time period. Meanwhile, the impacts of external environment on core temperature of power lines are brought into the calculation system. Through the research, the author analyzes the core temperature dynamic response of cable lines and figures up the actual core temperature of cable power lines.

\section{Equivalent subdivision of operational current}

Since cable load current in actual operation is constantly changed, temperature of cable conductors is also changed with the current change. The entire operational process is the transient process [4]. Even if the load current change is dynamic and continuous, the continuously changed current can be approximately decomposed into the form synthesized by the step change current, as shown in Figure 1. In the figure, $\mathrm{I}$ is the current; $\mathrm{t}$ is time. Unit time interval is $\Delta \mathrm{t}$, so the actual load current can be expressed by the following formula.

$$
i(t)=\sum_{x=0}^{y} a_{x} u(t-x \Delta t)
$$


In the formula, $\mathrm{u}(\mathrm{t})$ is the unit step change function; $\mathrm{ax}$ is the amplitude of current change; $\mathrm{x}$ and $\mathrm{y}$ are non-negative integers. The above-mentioned formula conducts Fourier transform to obtain its frequency spectrum function as:

$$
I(j \omega)=\sum_{x=0}^{y} a_{x}\left(\pi \delta(\omega+x \Delta \omega)+\frac{1}{j(\omega+x \Delta \omega)}\right)
$$

In the formula, $\delta(\omega)$ is the image function of the unit step change function $\mathrm{u}(\mathrm{t})$ - -the impulse function. Among which, frequency is $\omega=2 \pi / t$. The frequency variation is $\Delta \omega=2 \pi / \Delta t$. Formula (2) multiplies the transfer function of cable current temperature response and conducts inverse transformation of Fourier to obtain the real-time calculation formula of the cable conductor temperature.

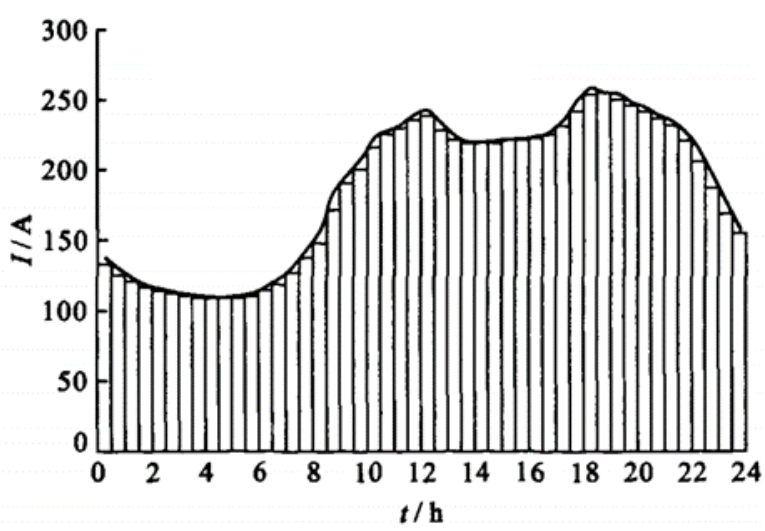

Figure 1 Step Change Subdivision of Actual Operation Current

\section{The core temperature of power lines in different environments}

$110 \mathrm{kV}$ crosslinked polyethylene's single core cables are used as research objects to design 3 temperature-rise tests of high-voltage cable emergency load variation with laying in water, laying in air, and burying in soil [5]. By comparing with Figure 2(a), (b) and (c), it can be observed that when current is suddenly changed, core temperature of cables at different laying environments has the different time to reach the steadiness. Among which, the transient variation of cables' core temperature in air is longest for about $6 \mathrm{~h}$. The transient variation of cables' core temperature in water is shortest for about 3h. The transient variation of cables' core temperature burying in soil is middle for about $5 \mathrm{~h}$.
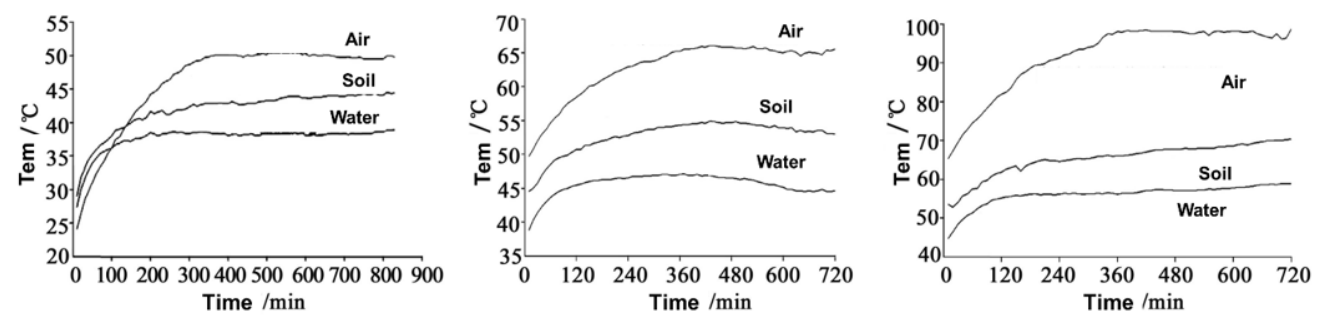

Figure 2 Cables' Core Temperature Variation with Time with the Mutation of Transmission Load Current

Thermocouple is paved in the pre-established temperature measurement point. The emergency current is uploaded to the initial load at the load device end. After loading, the automatic temperature measurement device records temperature data for once at $10 \mathrm{~min}$ interval. Table 1 shows the cables' core temperature variation gradient comparison within $3 \mathrm{~h}$ after current mutation at different laying environments. 
Table 1 Cables' Core Temperature Variation Gradient within 3h after Current Mutation at Different Laying Environments

\begin{tabular}{llccc}
\hline $\begin{array}{l}\text { Laying } \\
\text { environments }\end{array}$ & Time periods & 0A-800A & 800A-1000A & 1000A-1200A \\
\hline \multirow{2}{*}{$\begin{array}{l}\text { Cables laying in } \\
\text { water }\end{array}$} & 1h & 9.5 & 5.3 & 7.6 \\
& 2h & 2.2 & 1.5 & 3.1 \\
\multirow{5}{*}{ Cables laying in } & 3h & 0.9 & 0.7 & 0.8 \\
\cline { 2 - 4 } air & 2h & 10.4 & 5.7 & 10.2 \\
& $3 \mathrm{~h}$ & 5.5 & 3.5 & 6.9 \\
\cline { 2 - 4 } Cables burying & $1 \mathrm{~h}$ & 4.7 & 2.4 & 6.9 \\
in soil & $2 \mathrm{~h}$ & 9.0 & 4.7 & 4.1 \\
& 3h & 3.0 & 1.5 & 4.9 \\
\hline
\end{tabular}

It can be observed from Table 1 that when current takes place step change, cables' core temperature variation is not the same. When current is changed to $1200 \mathrm{~A}$ from $1000 \mathrm{~A}$, cables' core temperature variation gradient is maximum. When current is changed to $1000 \mathrm{~A}$ from $800 \mathrm{~A}$, cables' core temperature change gradient is minimum. In fact, laying environments cause a great impact on cables' core temperature change gradient. Among which, cables' core temperature variation gradient laying in air is maximum, while cables' core temperature variation gradient laying in water is minimum. The cables' core temperature variation gradient burying in soil is between them.

\section{The improved Laplace hot-line model}

In this paper, nodes in circuits are used to figure up core temperature of cable power lines. Since the current is continuously and gradually changed in actual cable operation, it is relatively difficult to directly solve the differential equation for the time-domain model. We consider the temperature field as a plane field and think heat transmission conducts lateral diffusion along cables to constitute in the cables' Laplace hot-line model:

$$
\begin{array}{rlrl}
\left(\mathrm{C}_{1}+\frac{1}{R_{1}}\right) \theta_{1}(\mathrm{~s})-\frac{1}{R_{1}} \theta_{2}(\mathrm{~s}) & & =\mathrm{Q}_{1}(\mathrm{~s}) & \\
-\frac{1}{R_{1}} \theta_{1}(\mathrm{~s})+\left(\mathrm{C}_{2}+\frac{1}{R_{1}}+\frac{1}{R_{2}}\right) \theta_{2}(\mathrm{~s})-\frac{1}{R_{2}} \theta_{3}(\mathrm{~s}) & \mathrm{Q}_{2}(\mathrm{~s}) & \\
-\frac{1}{R_{2}} \theta_{2}(\mathrm{~s})+\left(\mathrm{C}_{2}+\frac{1}{R_{2}}+\frac{1}{R_{3}}\right) \theta_{3}(\mathrm{~s})-\frac{1}{R_{3}} \theta_{4}(\mathrm{~s}) & =\mathrm{Q}_{3}(\mathrm{~s}) \\
-\frac{1}{R_{n-1}} \theta_{\mathrm{n}-1}(\mathrm{~s})+\left(\mathrm{C}_{\mathrm{n}}+\frac{1}{R_{n-1}}+\frac{1}{R_{n}}\right) \theta_{\mathrm{n}}(\mathrm{s}) & =\mathrm{Q}_{\mathrm{n}}(\mathrm{s})+\frac{1}{R_{n}} \theta_{4}(\mathrm{~s})
\end{array}
$$

In the formula, $\theta 1(\mathrm{~s})$ is the surface temperature of cable conductors; $\theta \mathrm{i}(\mathrm{s})(\mathrm{i}=2,3, \ldots, \mathrm{n}-3)$ is each layer's temperature of cables' main insulation(including internal and external shields). $\theta \mathrm{n}-2$ (s) is the cushion(including expansion zone) temperature; $\mathrm{C}$ is the thermal capacity of cable conductors; $\mathrm{Ci}(\mathrm{i}=2,3, \ldots, \mathrm{n}-3)$ is each layer's thermal resistance of cables' main insulation(including internal and external shields); $\mathrm{Rn}-2$ is the cushion(including expansion zone) thermal resistance; Rn-1 is air-gap thermal resistance; $\mathrm{Rn}$ is the cable over sheath(including anticorrosive coating) thermal resistance; Roj $(j=1,2, \ldots, m)$ is the surface medium thermal resistance from the external cable hot source to cable; $\mathrm{Q}(\mathrm{s})$ is the loss consumption generated by cable conductors; $\mathrm{Qi}(\mathrm{s})(\mathrm{i}=2,3, \ldots, \mathrm{n}-3)$ is each layer's dielectric loss of insulation; Qn(s) is the cable metallic shield loss. Considering that the 
thermal field and electric field have similarities, the method of frequency-domain analysis is used to calculate the core temperature step change current's dynamic response function of cables to achieve the goal of real-time calculation of cables' core temperature.

According to conclusions obtained by different laying environment tests, within 3h, cables' core temperature variation gradient laying in air is maximum; cables' core temperature laying in air has the longest time to reach the steady state and it is about 1.2 times of cables burying in soil and twice of cables laying in water. The surface temperature and cables' core temperature variation trends are basically consistent. As a result, for emergency power supply in a short time, it is necessary to focus on supervising the cable surface temperature variation laying in air (actual operation belongs to laying in tunnels), so as to evaluate cables' core temperature variation. In actual operation, cables generally belong to three-phase cables. In other words, 3 cables are simultaneously operated. Also, the impacts of another two cables as hot source in emergency load on operation of one cable's emergency load are analyzed. Formula (3) is transformed to obtain the following matrix expression.

$$
\mathrm{s} \Theta(\mathrm{s})-\Theta(0)=\mathrm{A} \Theta(\mathrm{s})+\mathrm{BQ}(\mathrm{s})
$$

In the formula,

$$
\Theta(0)=\left[\begin{array}{lll}
\theta_{1}(0) & \theta_{2}(0) & \theta_{3}(0), \ldots, \theta_{\mathrm{n}}(0)
\end{array}\right]^{\mathrm{T}} \text {; }
$$

$\mathrm{Q}(\mathrm{s})=\left[\mathrm{Q}_{1}(\mathrm{~s}) \mathrm{Q}_{2}(\mathrm{~s}) \quad \mathrm{Q}_{3}(\mathrm{~s}), \ldots, \mathrm{Q}_{\mathrm{n}}(\mathrm{s})+\frac{1}{R_{n}} \theta \mathrm{n}(\mathrm{s})\right]^{\mathrm{T}}$

$$
\begin{aligned}
& \mathrm{B}=\left[\begin{array}{cccc}
\frac{1}{C_{1}} & & & \cdots \\
& \frac{1}{C_{2}} & & \cdots \\
& \frac{1}{C_{3}} & \cdots \\
& & \vdots \\
& & \frac{1}{C_{N}}
\end{array}\right]
\end{aligned}
$$

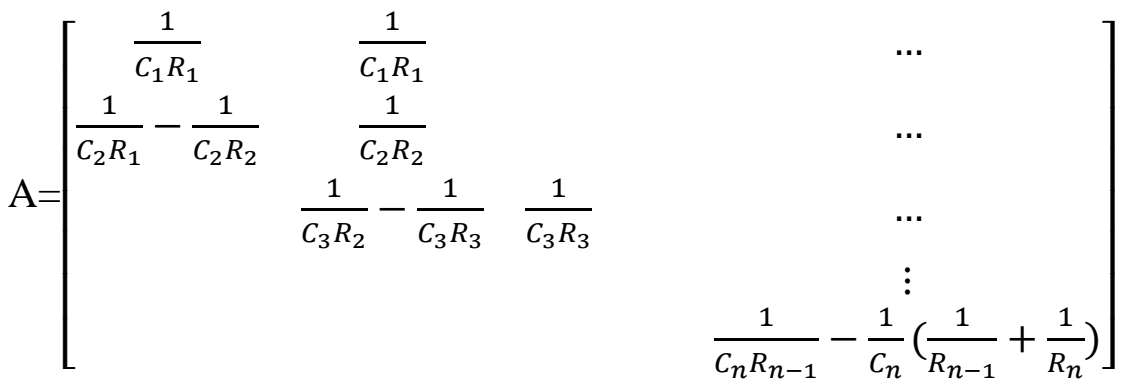

By dephasing and sorting out the Formula (4), I obtained:

$$
\Theta(s)=(S-A)^{-1} \Theta(s)+(S-A)^{-1} B Q(s)
$$

Formula (4) is the frequency-domain solution of the state equation. In the formula, $\Theta(0)$ is the initial temperature vector. By conducting Laplace transformation for the Formula (4), the time-domain of the state equation was:

$$
\theta(\mathrm{t})=\mathrm{L}^{-1}[\Theta(\mathrm{s})]=\mathrm{L}^{-1}\left[(\mathrm{~s}-\mathrm{A})^{-1} \Theta(0)\right]+\mathrm{L}^{-1}\left[(\mathrm{~s}-\mathrm{A})^{-1} \mathrm{BQ}(\mathrm{s})\right]
$$

\section{Conclusions}

Based on the cables' heat transfer theory, the author in this paper studied the cable transmission temperature response under the step change current and established the core temperature Laplace hot-line model of power lines based on the environmental impacts and operational current load. The model was featured as follows: by subdividing the step change current, continuously changed current was used as the input transformation for core temperature calculation of cable power lines. The improved hot-line model is based on cable laying environments. Considering the impacts of environmental changes on core temperature of power lines, it turned out to get close to actual core 
temperature, providing safeguard for safe operation of the power system. Core temperature change has hysteresis. Time constant is determined by heat capacity. The cable temperature dynamic hot-line model can effectively calculate real-time core temperature of lines and further accurately predict cables’ dynamic load flow to meet the actual engineering demands.

\section{References}

[1] Jin Haiyun, Zeng Yang and Ma Jiawei, Impacts of Degassing Thermal Treatment on 110kV Exchange XLPE Cable Insulating Mechanical Property and Dielectric Property[J], Insulating Materials, 2019(8).

[2] Zheng Naichuan, High-temperature Logging System Design and Realization Based on Power Line Carriers[D], 2015.

[3] Lei Chenghua, Liu Gang and Ruan Banyi, etc., the Experimental Study of High-voltage Single Core Cable's Dynamic Capacity Increasing According to Conductor's Temperature Rising Property[J], High-voltage Technology, 2012(6): 122-127.

[3] Dong Haiyan, Zhang Youpeng, and Dong Hailong, the Polluted Composite Insulator's Electric Field Property Analysis Based on the 3D Model[J], Journal of Lanzhou Jiaotong University, 2019, 38(3).

[4] Ma Qiwen, Chen Yongping and Gao Song, etc., the Research on Overhead Installation Operation Method of Bypass Cables[J], Shandong Power Technology, 2019(4). 